\title{
Anesthesia for Percutaneous Radiofrequency Tumor Ablation (PRFA): A Review of Current Practice and Techniques
}

This article was published in the following Dove Press journal: Local and Regional Anesthesia

\author{
Federico Piccioni $\mathbb{D}^{\prime}$ \\ Andrea Poli' \\ Leah Carol Templeton ${ }^{2}$ \\ $\mathrm{T}$ Wesley Templeton ${ }^{2}$ \\ Marco Rispoli ${ }^{3}$ \\ Luigi Vetrugno (iD) ${ }^{4}$ \\ Domenico Santonastaso ${ }^{5}$ \\ Franco Valenza $\mathbb{D}^{1,6}$ \\ 'Department of Critical and Supportive \\ Care, Fondazione IRCCS Istituto \\ Nazionale dei Tumori, Milan, Italy; \\ ${ }^{2}$ Department of Anesthesiology, Wake \\ Forest University, Winston-Salem, NC, \\ USA; ${ }^{3}$ Anesthesia and Intensive Care \\ Unit, V. Monaldi Hospital, Naples, Italy; \\ ${ }^{4}$ Anesthesia and Intensive Care Unit, \\ Santa Maria della Misericordia University \\ Hospital, Udine, Italy; ${ }^{5}$ Anesthesia and \\ Intensive Care Unit, M. Bufalini Hospital, \\ Cesena, Italy; ${ }^{6}$ Department of Oncology \\ and Onco-Hematology, University of \\ Milan, Milan, Italy
}

\begin{abstract}
Percutaneous radiofrequency ablation (PRFA) of solid tumors is a minimally invasive procedure used to treat primary or metastatic cancer lesions via needle targeted thermal energy transfer. Some of the most common tumor lesions treated using PRFA include those within the liver, lungs and kidneys. Additionally, bone, thyroid, and breast lesions can also be treated. In most cases, this procedure is performed outside of the operating room in a specialized radiology suite. As a result, the clinician must adapt in many cases to the specific environmental issues attendant to providing anesthesia outside the operating room, including the lack of availability of an anesthesia machine in some cases, and frequently a lack of adequate scavenging and other specialized monitoring and equipment. At this time, routine practice and anesthetic prescriptions for PRFA can vary widely, ranging from patients receiving local anesthesia alone, to monitored anesthesia care, to regional anesthesia, to combined regional and general anesthesia. The choice of anesthetic technique will depend on tumor location and practitioner experience. This review aims to summarize the current state of the art in terms of anesthetic techniques for patients undergoing PRFA of solid tumors.
\end{abstract}

Keywords: anesthesia, conduction, deep sedation, conscious sedation, neoplasms, radiofrequency ablation, radiography, interventional

\section{Introduction}

Percutaneous radiofrequency ablation (PRFA) of solid tumors is a minimally invasive procedure intended to treat primary and/or metastatic solid tumors via thermal tissue destruction as a result of targeted thermal energy deposition and coagulative necrosis. ${ }^{1,2}$ The procedure is performed using $14-21 \mathrm{G}$ partially insulated needle electrodes connected to a radiofrequency generator. The electrode is usually expandable and multi-tined so that, when deployed and extended, it can treat lesions up to $5 \mathrm{~cm}$ in diameter. The area of necrosis is dependent on the temperature achieved at the level of the tissue and the duration of heating. ${ }^{1,2}$ Typically, tissue necrosis is achieved at a temperature of $60-100^{\circ}$ $\mathrm{C}$ for 4-6 mins, but in cases where thermal conduction into the lesion is slow, the duration of application may need to increase to as much as 20-30 mins. ${ }^{1,2}$ With PRFA, the most commonly treated lesions at this time are those within the liver, lung and kidney, but the role of PRFA in other solid tumors appears to be expanding with applications now in pancreatic, soft tissue, bone and thyroid neoplasms. ${ }^{1-3}$

From an anesthetic standpoint, the clinician's goal, as always, must be to alleviate or moderate procedural discomfort while also facilitating the performance
Department of Critical and Supportive Care, Fondazione IRCCS Istituto Nazionale dei Tumori, Via Venezian I, Milan 20133, Italy Tel +39223902282

$\mathrm{Fax}+39223903366$

Email federico.piccioni@istitutotumori.mi.it 


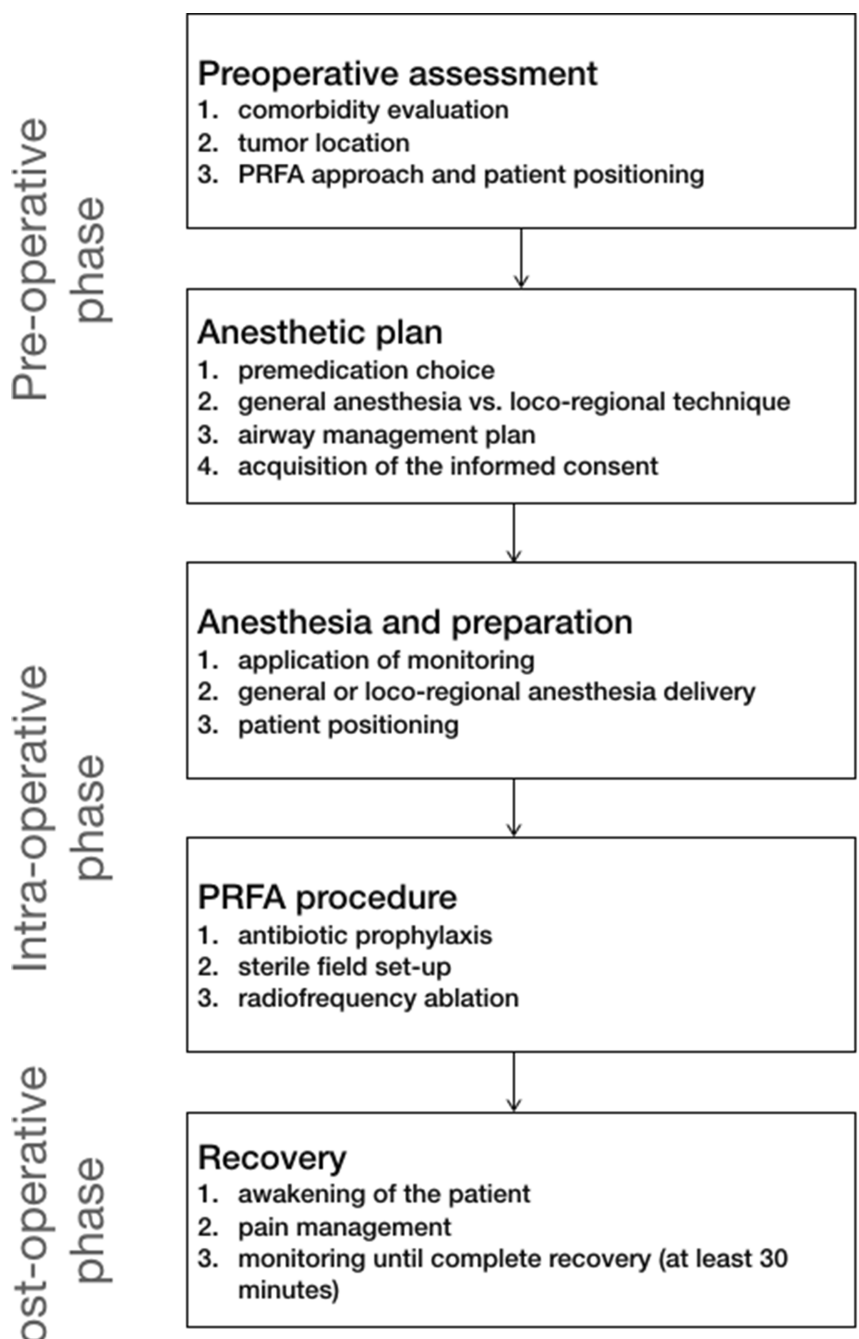

Preoperative patient assessment is crucial for risk stratification. In this step the anesthesiologist shall acquire the information on the tumor location and the subsequent PRFA strategy.

The anesthetic plan must be clearly defined before the procedure and shared with the radiologist. Also, the patient must be informed on it to enhance his engagement in the treatment. Careful airway management plan is mandatory to ensure the highest level of safety.

Both general and loco-regional anesthesia must be managed according to maximum safety standards. Great attention must be paid to patient positioning to avoid discomfort and to ensure prompt access to airway and venous access. Medications and equipment for emergence must be always promptly available.

The PRFA is usually performed under ultrasound or CT-scan guidance. The procedure may need several electrode insertions according to the tumor location and size. Usually the radiologist perform local anesthesia.

If necessary, the recovery from anesthesia can be managed in the Post Anesthesia Care Unit (PACU) or in the Intensive Care Unit (ICU) for frail and high risk patients.

Figure I An overall workflow diagram of PRFA from the anesthesiologist's point of view.

of the procedure. In general, the two primary stimuli are the initial skin puncture as well as the deeper pain associated with thermal tissue necrosis. In some cases, especially with lesions of the liver and lung, patient cooperation may actually help facilitate accurate lesion and needle localization making monitored anesthesia care (MAC) by itself or in combination with regional anesthesia the technique of choice. In other cases, the patient may not be able to tolerate the procedure without general anesthesia. Unfortunately, because many patients with these lesions have significant comorbidities, they may also not be ideal surgical candidates and may be at increased risk of complications from general anesthesia requiring the clinician to very carefully consider an anesthetic prescription which keeps benefits and risks appropriately in balance. As a result, there is no overall consensus on the best anesthetic approach to patients undergoing PRFA. This review summarizes the current state of the art for different anesthetic techniques used for a patient undergoing PRFA of solid tumors.

\section{Overview and Preoperative Evaluation for PRFA Procedures}

PRFA in many cases is performed under ultrasound guidance but also can be performed using CT or MRI. ${ }^{1,2}$ As a result, this procedure is commonly performed outside of the operating room. In general terms, non-operating room anesthesia (NORA) has become essential in the delivery of procedural care in the modern era, as ever-increasing numbers of these cases are performed outside of the operating room. While the characteristics of these procedures vary, in many cases, these invasive procedures require the utilization of anesthesia to 
provide the proceduralist with optimal conditions. To safely provide NORA in remote locations, it is imperative that the clinician perform a focused preoperative evaluation and make adequate on-site preparations. In addition to making standard airway and monitoring equipment available such as an appropriately sized supraglottic airway and end-tidal carbon dioxide monitoring, the clinician must also have contingency plans in place to deal with crisis management and post-procedure recovery.

In most cases, a thorough pre-operative patient evaluation should be performed; however, there are specific areas that should be addressed when preparing for PRFA and NORA in these frequently at-risk patients. Special attention should be focused on both cardiovascular and pulmonary comorbidities. Additionally, the clinician should specifically inquire about the current use of anticoagulant medications as these patients may frequently be prescribed these medications which can vary significantly in terms of their mode of action and potency with significant procedural and hemostatic consequences. Specific patient populations may also have specific organ function-related embarrassment that should be considered when developing a given anesthetic prescription. Specifically, patients with liver cancer often have associated cirrhosis and attendant hemostatic disorders which will result in an increased risk of bleeding. The proceduralist and the anesthesia provider will need to agree on acceptable values for crucial values, such as hemoglobin and platelet levels prior to proceeding and obtain necessary blood products and/or transfuse the patient prior to undergoing a procedure. Another example of this is that patients undergoing PRFA for lung tumor may have decreased pulmonary reserve and frequently are at high risk for post-procedural pneumothorax and consequently may require a chest tube following lesion ablation.

More generally, it is important that patients be evaluated pre-operatively for the presence of risk factors that may contribute to increased rates of respiratory complications. In addition to the presence of chronic obstructive pulmonary disease, providers should also assess indices and historical factors that may be suggestive of obstructive sleep apnea (OSA) or sleep-disordered breathing. Indices suggestive of OSA include body mass index (BMI) $>45 \mathrm{~kg} / \mathrm{m}^{2}$ and neck circumference of $40 \mathrm{~cm}$. Other historical findings suggestive of OSA or sleep-disordered breathing include daytime somnolence and/or regular daytime headaches. This is important because the presence of OSA and sleep-disordered breathing may significantly increase the risk of adverse respiratory events both during and following general anesthesia or MAC. Similarly, obesity (BMI $>30 \mathrm{~kg} / \mathrm{m}^{2}$ ), and especially morbid obesity with or without OSA, may increase the potential for airway obstruction even in the setting of mild sedation. This can become significant in patients undergoing MAC for kidney or lung PRFA where airway rescue maneuvers may become necessary in the prone position. As a consequence, the clinician may elect to go ahead and secure the airway prior to prone positioning to assure procedural safety. Other potential options may include substantially reducing the depth of sedation with agents such as ketamine or dexmedetomidine. Either way, it is important for the clinician to assess the risk and benefits of any given approach in the setting of NORA for these types of procedures.

Finally, the clinician should always take an adequate history and/or examine previous records to determine if airway management has been challenging in the past. Further, the clinician should perform a comprehensive airway exam prior to sedation or induction of general anesthesia to identify patients that may have indices such as poor mouth opening, decreased cervical range of motion, or shortened thyromental distance suggestive of a difficult airway. This is relevant in this population, as many of these patients may have airway issues as a result of their underlying age and disease state which may affect the clinician's anesthetic choice and approach to airway management for PRFA. For example, in patients that appear to be challenging, the clinician may elect to avoid dealing with the airway all together and use a regional technique or they may elect to have video laryngoscopy or a flexible fiberoptic scope available in cases where general anesthesia appears most appropriate. In situations where the airway appears favorable, the clinician may feel more comfortable using sedation and MAC with a native airway. In the case of patients undergoing PRFA, there may be multiple approaches to achieve success, but the clinician must weigh the risks and benefits of any given technique in the setting of a given patient and procedure to develop an optimal approach and anesthetic plan.

\section{Intraprocedural Management of PRFA}

Because many PRFA procedures are performed in remote locations, the clinician performing anesthesia and sedation for these procedures should have experience specific to NORA to ensure patient comfort and safety. Further, the clinician must be aware of issues related specifically to various PRFA procedures in addition to being able to respond to periprocedural adverse events and directing other non-anesthesia providers to assist in the case of such an event (Table 1). 
Table I Anesthesia Techniques and More Frequent Problems to Face During the Different Types of PRFA

\begin{tabular}{|c|c|c|c|c|}
\hline $\begin{array}{l}\text { PRFA } \\
\text { Location }\end{array}$ & Patient Positioning & Anesthesia & Anesthesiology Concerns & $\begin{array}{l}\text { Most Frequent } \\
\text { Intraoperative } \\
\text { Complications }\end{array}$ \\
\hline Liver & Supine & $\begin{array}{l}\text { GA, LA + MAC, } \\
\text { TPVB, TEA }\end{array}$ & $\begin{array}{l}\text { Need for deep breath and apneic pause; acute } \\
\text { pain for subglissonian or near the parietal } \\
\text { peritoneum tumor }\end{array}$ & $\begin{array}{l}\text { Hemorrhage, } \\
\text { pneumothorax, bile duct } \\
\text { injury, colonic perforation }\end{array}$ \\
\hline Kidney & $\begin{array}{l}\text { Lateral, semi-prone, } \\
\text { prone }\end{array}$ & $G A, L A+M A C$ & $\begin{array}{l}\text { Difficult airway management in case of } \\
\text { respiratory failure during sedation in prone } \\
\text { position; need for apneic pause; acute pain for } \\
\text { bowel or ureteral injury }\end{array}$ & $\begin{array}{l}\text { Colonic perforation, } \\
\text { ureteral injury, } \\
\text { hemorrhage }\end{array}$ \\
\hline Lung & Supine, lateral, prone & $\begin{array}{l}\mathrm{GA}, \mathrm{LA}+\mathrm{MAC} \\
\text { TPVB, TEA, ICNB }\end{array}$ & $\begin{array}{l}\text { Coughing, dyspnea, difficult airway } \\
\text { management in case of respiratory failure } \\
\text { during sedation in prone position; need for } \\
\text { apneic pause }\end{array}$ & $\begin{array}{l}\text { Pneumothorax, } \\
\text { hemorrhage }\end{array}$ \\
\hline Bone & Supine, lateral, prone & $G A, L A+M A C$ & $\begin{array}{l}\text { Difficult airway management in case of } \\
\text { respiratory failure during sedation in prone } \\
\text { position; dyspnea during rib tumor treatment; } \\
\text { pain due to injury of structures near the } \\
\text { ablation site }\end{array}$ & $\begin{array}{l}\text { Pneumothorax, injury of } \\
\text { structures near the } \\
\text { ablation site (liver, bowel, } \\
\text { nerves, vessels) }\end{array}$ \\
\hline Pancreas & Supine & $\mathrm{GA} \pm \mathrm{TEA}, \mathrm{LA}+\mathrm{MAC}$ & $\begin{array}{l}\text { Need for deep breath and apneic pause; post- } \\
\text { procedural severe pain }\end{array}$ & $\begin{array}{l}\text { Hemorrhage, duodenal } \\
\text { perforation }\end{array}$ \\
\hline Adrenal gland & $\begin{array}{l}\text { Lateral, semi-prone, } \\
\text { prone }\end{array}$ & $G A, L A+M A C$ & $\begin{array}{l}\text { Difficult airway management in case of } \\
\text { respiratory failure during sedation in prone } \\
\text { position; need for apneic pause; arterial } \\
\text { hypertension }\end{array}$ & $\begin{array}{l}\text { Colonic perforation, } \\
\text { hemorrhage }\end{array}$ \\
\hline Thyroid & Supine & GA, LA, LA + MAC & Dyspnea, local pain & $\begin{array}{l}\text { Hematoma, dysphagia, } \\
\text { temporal voice change }\end{array}$ \\
\hline Breast & Supine & $G A, L A+M A C$ & Local pain & Hematoma \\
\hline
\end{tabular}

Abbreviations: GA, general anesthesia; LA, local anesthesia; MAC, monitored anesthesia care; TPVB, thoracic paravertebral block; TEA, thoracic epidural anesthesia; ICNB, intercostal nerve block.

NORA generally requires that the all standard monitoring, airway equipment, anesthetic drugs and any additional resuscitation equipment be available from the outset of any given case. Standard monitoring during PRFA should include pulse oximetry, ECG, non-invasive blood pressure and capnography for early detection of respiratory problems. ${ }^{4-6}$ Processed EEG devices may be useful to avoid excessive sedation but are not mandatory. In cases of patients with significant coronary disease or other cardiac conditions such as congestive heart failure, the clinician may want to consider the placement of an arterial line. Additionally, the availability of a secondgeneration supraglottic airway device is mandatory, as they are a suitable airway rescue device and can allow for both oxygenation and ventilation in an emergency situation. Further, they can be used to facilitate tracheal intubation if necessary. Capnography should always be available and utilized in patients undergoing general anesthesia. Additionally, the authors strongly advocate following the guidelines of the ASA for the utilization of capnography in all patients receiving sedation and MAC with a native airway. Finally, sufficient space must be always allocated to the anesthesiologist and all anesthesia equipment to facilitate routine and emergent maneuvers. Box 1 summarizes the main equipment that the authors recommend should be present in an environment where PRFA procedures are performed.

The prevention of infections is another important issue regarding PRFA. Performing invasive procedure outside the operating room is potentially a risk factor for contamination of the surgical field. There is no consensus on the need for antibiotic prophylaxis before PRFA. The 2018 guidelines on antibiotic prophylaxis during vascular and interventional radiology procedures edited by the Society of Interventional 
Box I Minimum Mandatory Anesthesia Equipment for PRFA Procedures

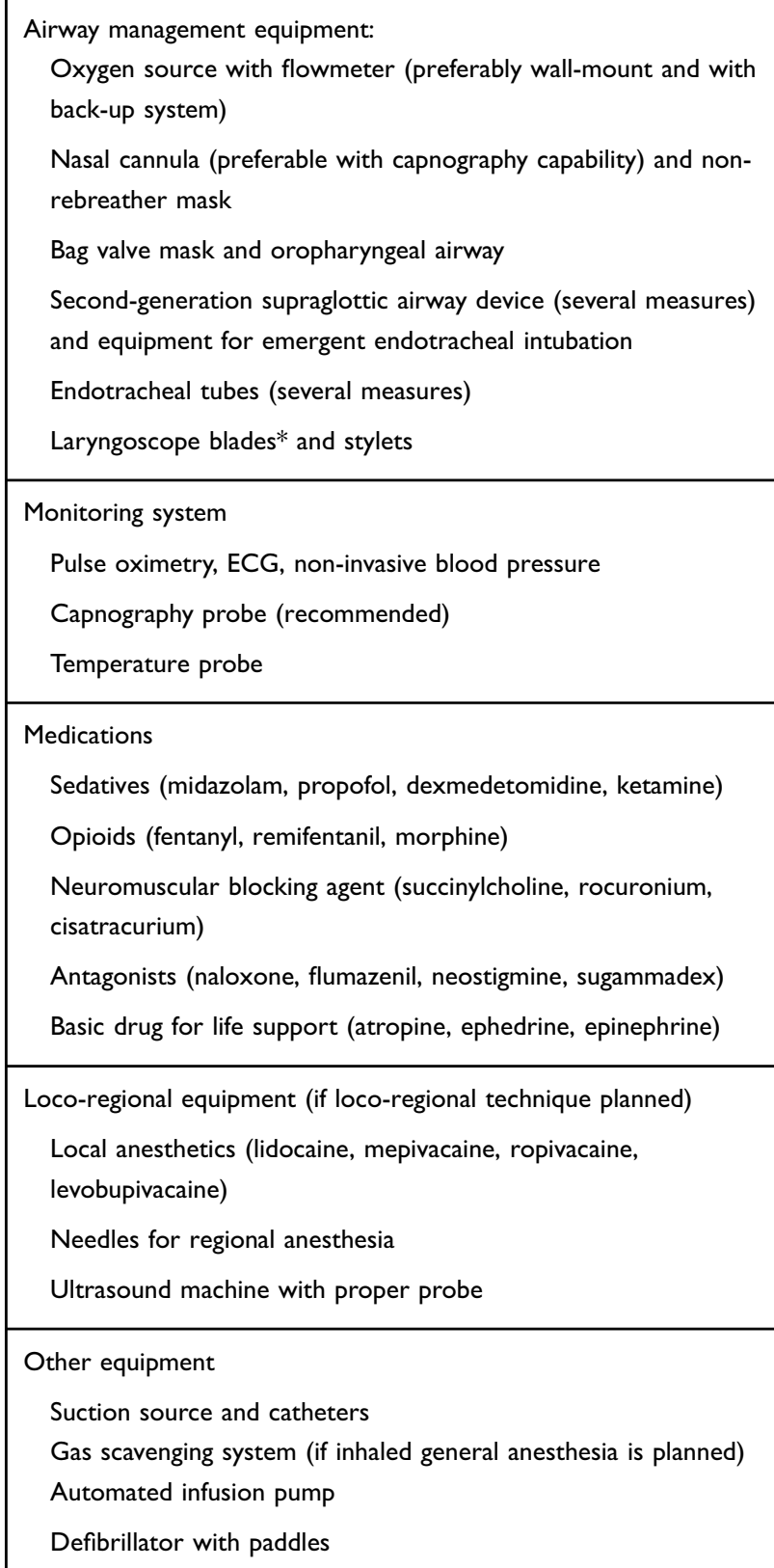

Note: *The availability of a videolaryngoscope is advisable for patients screened for borderline predicted difficult intubation, morbidly obese patients and when the subject position during the procedure may increase the difficulty of intubation.

Radiology recommend routine prophylaxis only for liver tumor ablation. ${ }^{7}$ In low-risk patients, the guidelines recommend the administration of iv cefazolin $1-2 \mathrm{~g}$. In patients at high risk for postoperative infection (eg cirrhosis, diabetes, history of biliary-enteric anastomosis), several regimens are proposed: levofloxacin combined with metronidazole, neomycin and erythromycin; ampicillin/sulbactam; vancomycin or clindamycin with gentamicin. Finally, the guidelines do not recommend routine antibiotic prophylaxis for patients undergoing renal, lung, adrenal or bone tumor radiofrequency ablation. Further, to minimize the risk of infection, rigorous antiseptic handling of loco-regional equipment (eg. needle, ultrasound probe) and a careful dressing of the surgical field are essential to guarantee an adequate level of asepsis.

At the end of the procedure, patients must be monitored at least for $30 \mathrm{mins}$ in a properly equipped recovery location. ${ }^{4}$ This area is usually included in the interventional radiology facility and rigorous discharge criteria must be applied before return (eg. the ALDRETE score). ${ }^{4}$ If needed, the patient must be transferred to the post-anesthesia care unit (PACU) or the intensive care unit (ICU). This evidence must be properly managed by the anesthesiologist who must be properly equipped for patient transfer with portable mechanical ventilator and vital signs monitor. Figure 1 summarizes PRFA workflow from the anesthesiologist's point of view.

\section{Specific PRFA Procedures PRFA for Liver Tumors}

Primary and metastatic liver tumors are the most frequent indications for PRFA. PRFA for hepatocellular carcinoma is also used as a bridge therapy for liver transplantation. ${ }^{1,8,9}$ In many cases, PRFA is reserved for patients deemed not suitable for surgical resection of the mass secondary to poor hepatic reserve, advanced cancer stage, severe comorbidities or advanced age. PRFA for liver tumor has mortality and major complication rates reported to be $0.15 \%$ and $4.1 \%$, respectively, although this data was pooled from patients with liver tumors receiving PRFA, microwave ablation, and percutaneous ethanol injection of tumors. ${ }^{10}$

In most cases, the anesthetic choice for radio frequency ablation of the liver is dependent on the surgical approach that is planned. More specifically, video-laparoscopic approaches require general anesthesia versus percutaneous approaches which can be performed with local infiltration and MAC. In general, video-laparoscopic approaches are typically indicated for the treatment of lesions that may be difficult to target via percutaneous puncture or the approach may be utilized when radio frequency ablation is performed as part of a staging procedure. In certain situations, general anesthesia may also be necessary for liver PRFA. Recently, Beerman et al reported their experience with PRFA of liver lesions performed under general anesthesia. ${ }^{3}$ Interestingly, the authors reported the use of high-frequency jet ventilation as a way of reducing the 
amplitude of respiratory movements to create near static conditions of both the upper-abdominal and intrathoracic organs allowing for greater surgical precision.

Whenever possible though, the percutaneous treatment approach in combination with local infiltration and MAC is preferred. In most cases, this approach can provide adequate anesthesia and analgesia with the possibility of fewer anesthetic-related side effects. Further, in some cases depending on the location of the lesion, this technique may allow for the patient to cooperate and thereby facilitate the performance of the procedure via indirect liver mobilization by ensuring that the patient is able to take a deep breath and/or hold their breath for a brief apneic pause at the request of the proceduralist.

When planning the anesthetic for percutaneous liver RFA, it is important to note that there appear to be three main sources of pain during the PRFA of liver lesions. These are the skin puncture, the glissonian capsule, and the thermal energy transfer. Additionally, this tends to be more painful when the treated lesion is subglissonian or near the parietal peritoneum. ${ }^{9}$ One anesthetic approach is to provide local anesthesia via infiltration at the puncture site and at the needle tract down to and including the glissonian capsule using $2 \%$ lidocaine. $^{11,12}$ Following infiltration of the local anesthetic, sedation is provided by administering one or more of the following: propofol, midazolam, diazepam, remifentanil or fentanyl.,13,14 Where available, a target-controlled infusion (TCI) regimen can be used to optimize the delivery of propofol and remifentanil and enhance recovery at the end of the procedure. ${ }^{15}$ In situations where this is not available, the clinician can still provide adequate sedation using patient feedback and appropriate monitoring.

Currently, this area represents a fertile area of research with numerous anesthetic prescriptions for PRFA being studied including the use of pethidine as a sole intravenous anesthetic. ${ }^{11}$ Additionally, Wu et al have reported the use of a single dose of intravenous oxycodone $0.1 \mathrm{mg} / \mathrm{kg} 15 \mathrm{mins}$ prior to PRFA and compared that to a continuous infusion of remifentanil during the procedure. Ultimately, they found that intravenous oxycodone increased both patient satisfaction and pain relief after the procedure. ${ }^{12}$ It should be noted that dexmedetomidine was administered as an additional sedative in both study arms. In another randomizedcontrolled trial by Joung et al, the investigators compared a combination of dexmedetomidine and remifentanil with the combination of propofol and remifentanil for PRFA. ${ }^{16}$ In this trial, the dexmedetomidine and remifentanil combination provided better respiratory stability defined as a smaller change in post-procedure $\mathrm{PaCO}_{2}$ via arterial blood gas and reduced post-procedure opioid consumption when compared to the propofol/remifentanil arm. More recently, investigators have proposed using a dezocine-remifentanil combination and actually found this to be more effective than a combination of midazolam-remifentanil. ${ }^{17}$ In summary, many of these results come from fairly small studies with high rates of procedural success in different study arms. Therefore, the clinician should exercise some degree of caution and not over-interpret the results of these studies, continuing to apply their expert clinical judgement in developing an anesthetic prescription for any given patient that takes into account their experience and what is available at their facility. Table 2 summarizes suggested dosages of sedatives and opioids commonly used for sedation during PRFA.

Other centers have combined regional anesthesia techniques with MAC to provide anesthesia for these procedures in patients with liver tumors. In 2009, Wong et al reported the use of a thoracic paravertebral block (TPVB) for selected PRFA procedure. ${ }^{18}$ Two years later, Cheung Ning described the use of right TPVB for PRFA under propofol-based sedation. ${ }^{19}$ In 2014, Piccioni et al described the use of TPVB as the sole anesthetic in a case series of 12 patients using only two nerve stimulator-guided injections at the T7 and T9 paravertebral spaces. ${ }^{20}$ Additionally, Gazzera et al also reported their experience using ultrasound-guided TPVB for PRFA. ${ }^{21}$ Interestingly though, for cases involving a subcapsular hepatic lesion, they also performed an additional right cervical phrenic nerve block with $3 \mathrm{~mL}$ of

Table 2 Suggested Dosage for Most Used Hypnotics and Opioids For Sedation During PRFA

\begin{tabular}{|c|c|}
\hline Medication & Dosage \\
\hline \multicolumn{2}{|l|}{ Hypnotics } \\
\hline Propofol & $\begin{array}{l}\text { Loading dose: } 0.5-1 \mathrm{mg} / \mathrm{kg} \\
\text { Maintenance: } \mathrm{I}-3 \mathrm{mg} / \mathrm{kg} / \mathrm{h} \\
\text { TCl effect-site concentration: } 2-4 \mathrm{mcg} / \mathrm{mL}\end{array}$ \\
\hline Midazolam & Bolus dose: $0.02-0.1 \mathrm{mg} / \mathrm{kg}$ \\
\hline Dexmedetomidine & $\begin{array}{l}\text { Loading dose: I mcg/kg over } 15 \mathrm{mins} \\
\text { Maintenance: } 0.1-0.2 \mathrm{mcg} / \mathrm{kg} / \mathrm{h}\end{array}$ \\
\hline \multicolumn{2}{|l|}{ Opioids } \\
\hline Remifentanil & $\begin{array}{l}0.05-0.15 \mathrm{mcg} / \mathrm{kg} / \mathrm{min} \\
\mathrm{TCl} \text { effect-site concentration: } \mathrm{I}-3 \mathrm{ng} / \mathrm{mL}\end{array}$ \\
\hline Fentanyl & Bolus dose: $0.5-1 \mathrm{mcg} / \mathrm{kg}$ \\
\hline
\end{tabular}


lidocaine $2 \%$ to further improve procedural tolerance. This trend continues with other recent studies recapitulating that TPVB appears to be more effective than local anesthesia for PRFA of liver tumors. ${ }^{22,23}$ This is likely a result of TPVB producing a unilateral somatic and sympathetic nerve blockade with the local anesthetic spreading to the epidural and intercostal spaces further extending the analgesic effect beyond the procedural epoch. ${ }^{24}$

Thoracic epidural anesthesia (TEA) represents another regional anesthetic technique that has been adopted by some groups for PRFA of liver tumors. ${ }^{25,26}$ Theoretically, TEA may provide a denser block than local anesthesia and/or TPVB, but its execution may be associated with increased risks, as many of these patients may have significant in situ coagulopathies from reduced levels of clotting factors. Further, TEA may lead to an increased risk of hemodynamic instability. ${ }^{27}$ While there are no large studies comparing different anesthetic techniques, the authors of this review feel there is increasing evidence that the TPVB may represent the regional anesthetic of choice for these procedures. Conversely, albeit in the absence of comparative studies, TEA seems not to give a real advantage over TPVB for PRFA, especially when considering its greater invasiveness and relative more complex management.

In summary, liver PRFA can be managed in many ways by anesthesiologists. There is no adequate comparative study to draw conclusions about which is the best technique but the authors suggest to avoid general anesthesia whenever possible in order to enhance the patients' recovery and to decrease the need for post-procedural care.

\section{PRFA for Kidney Tumors}

Small kidney tumors $(\leq 3 \mathrm{~cm})$ in patients unsuitable for surgery can be treated with PRFA. ${ }^{1,28,29}$ Needle localization is typically performed under ultrasound guidance, with CT used for anatomic confirmation. Patients are usually positioned in the lateral, semi-prone or prone position to avoid peritoneal trauma. These are frequently used in combination with hydrodissection to displace the bowel, thereby decreasing the risk of injury and minimizing pain. In patients with tumors near the ureter, a ureteral stent can also be placed to decrease the risk for injury. Major sources of pain for these procedures include the ureter and bowel, especially if they are in proximity to the cancer, and therefore these issues must be taken into account in planning an appropriate anesthetic.
Kidney PRFA can be performed under general anesthesia or local infiltration with MAC. ${ }^{30-36}$ Local infiltration is typically performed with an injection of $5-10 \mathrm{~mL}$ of $2 \%$ lidocaine at the skin and through the needle tract used to access the lesion. In addition to local anesthesia at the site, sedation with hypnotics such as midazolam or droperidol and/or opioids such as fentanyl or meperidine can also be used to improve patient comfort for this procedure. ${ }^{32,33,35}$ In contrast to this, Park et al have reported their experience with intravenous pethidine alone to improve awareness under anesthesia with the aim of real-time feedback to prevent inadvertent injury to surrounding structures like the genitofemoral nerve. ${ }^{34}$ Recently, Kim et al have compared the efficacy of MAC with midazolam and fentanyl administration to general anesthesia for kidney PRFA. ${ }^{36}$ Interestingly, they found both better local tumor control and 3-year recurrence-free survival rates in patients treated under GA when compared to patients receiving MAC. While the etiology of this remains unclear, the authors have theorized that better pain relief during general anesthesia resulted in increased time of PRFA treatment with patients in the general anesthesia group undergoing a median treatment time of 25 vs 16 mins in those receiving MAC $(p<$ 0.001). Additionally, the authors theorize that there is greater precision in targeting the tumor under general anesthesia as a result of controlled respiratory pauses. Ultimately though, these findings must be evaluated with some caution given the retrospective study design and the small sample size, with 10 patients in the MAC group versus 41 patients in the general anesthesia group.

Thus, general anesthesia is probably the safest approach for patients at high risk of respiratory failure or complex procedure when performed in the semi-prone or prone position. Also, the feasibility of kidney PRFA under local anesthesia and MAC is widely proven, and this approach can be adopted on a case-by-case basis, especially for procedures performed in lateral position.

\section{PRFA for Lung Tumors}

PRFA for lung tumors is mainly performed to treat earlystage non-small cell lung cancer (NSCLC) in high-risk patients not suitable for surgery. ${ }^{1,37}$ In these cases, PRFA is often combined with radiotherapy and chemotherapy and is performed under CT guidance. Other indications for lung PRFA include the treatment of small metastatic lung lesions and palliative treatment of large tumors causing symptoms such as pain and intractable cough. ${ }^{38}$ Mortality and major complications are quite low after PRFA for lung masses, $0.4 \%$ and $8-12 \%$, respectively. ${ }^{39,40}$ Not surprisingly, 
pneumothorax is the most common complication after lung PRFA (20-25\%), ${ }^{1,3}$ with a post-operative chest tube insertion rate between 4 and $16 \%{ }^{41,42}$ The main sources of pain are the puncture site, the pleura, and in some cases the diaphragm. Depending on the location of the tumor, the patient is positioned in the supine, prone or lateral position. Historically, general anesthesia has been the anesthetic of choice for these procedures in most cases because general anesthesia provides the most controlled conditions under which the procedure can be performed. General anesthesia is frequently chosen as it results in reduced patient movement. During this procedure the incidence of coughing can be significant, as a result of the movement of the radio frequency needle, and/or the thermal stimulus, especially when the radio frequency needle is near bronchial structures, or lastly as a result of a new pneumothorax. ${ }^{42,43}$

MAC with local infiltration can be used to provide anesthesia for these procedures but is a second choice when compared to general anesthesia for the reasons of coughing and patient movement highlighted above. ${ }^{3,43}$ At this time, there are several case series of lung PRFA successfully performed under and MAC and local infiltration using midazolam or propofol in combination with fentanyl or remifentanil. ${ }^{4-46}$ Further, Hoffman has published a small retrospective study comparing MAC and local infiltration with general anesthesia for lung PRFA which found no difference with regard to PRFA success or patient complications. ${ }^{46}$ Based on these findings, it may be reasonable in certain situations to consider MAC with local infiltration for this procedure but careful patient selection is likely to contribute substantially to procedural success.

The adoption of regional anesthetic techniques as the primary anesthetic for lung PRFA is not widespread at this time, although some authors have suggested its use to enhance post-procedural analgesia. Yasui et al have reported the use of thoracic epidural anesthesia for patients with tumors located beneath the pleura undergoing PRFA. ${ }^{47}$ Recently, Ruscio et al also have published a case report describing the use of TPVB for post-operative analgesia after PRFA treatment of a left lower lobe tumor. ${ }^{48}$ Additionally, intercostal nerve blocks and TPVBs have been performed for post-procedure analgesia for PRFA of lung tumors associated with rib ablation, reported by vanSonnenberg et al. ${ }^{49}$

In summary, general anesthesia appears to be the anesthetic technique of choice for patients undergoing PRFA of lung tumors with some authors investigating the possibility of certain regional techniques to reduce post-procedural pain.
Based on the authors' personal experience, MAC with local infiltration is an effective approach but the anesthesiologist must pay close attention to the respiratory function and always be ready to assist the patient with a facial mask and, if necessary, with supraglottic device insertion or tracheal intubation. Clearly more prospective study is necessary to clarify the potential role and risk-benefit ratio of regional anesthesia for patients undergoing this procedure.

\section{PRFA for Bone Tumors}

PRFA is commonly used for the treatment of osteoid osteomas and may represent another option for the treatment of metastatic bone disease, although this remains investigational at this time. ${ }^{1,50,51}$ It is well known that the presence of bone metastasis usually worsens a patient's quality of life as a result of significant pain and the occurrence of pathologic fractures. In some cases, PRFA may now be used as an alternative to palliative radiotherapy and can further be combined with medical therapy to reduce patient suffering. This is supported by the work of several groups who have reported the efficacy of PRFA in reducing both pain and consumption of analgesics after treatment of bone metastasis. ${ }^{52-55}$ Depending on the stiffness of the tumor tissue, straight or expandable RFA needles are used. In the case of a large lesion, usually $>3-4 \mathrm{~cm}$, multiple electrode placements may be necessary. Furthermore, because the procedure can involve different areas such as the chest wall, spine, pelvis, and extremities, patient positioning can vary greatly and sedation may be necessary to allow patient tolerance of a given position. Bone PRFA can be performed under general anesthesia or under MAC. ${ }^{52-56}$ Usually local infiltration with $2 \%$ lidocaine is provided intradermally and around the periosteum. Sedation is most commonly performed with benzodiazepines such as midazolam or bromazepam and opioids such as pethidine or fentanyl. ${ }^{54-56}$ Theoretically, anesthesia for bone PRFA could be provided under regional anesthesia alone, especially when performed on an extremity but currently, there is a lack of available literature, case based or otherwise, on which to base any recommendations. Thacker et al have reported the use of combined general and regional anesthesia in a small case series but at this time there are no large prospective studies to guide best practices. ${ }^{57}$

\section{Other Application of PRFA for Tumor}

PRFA can also be used to treat many other solid primary or metastatic tumors involving the pancreas, adrenal gland, thyroid, and breast. ${ }^{3,58-64}$ Pancreas, adrenal gland and 
thyroid PRFA are usually performed under local infiltration and MAC. Thyroid PRFA can be also performed under local infiltration alone without the aid of sedation given the shallow depth of the gland and frequent brevity of the procedure. In fact, this approach has been endorsed by the Korean Society of Thyroid Radiology in their recently published guidelines. ${ }^{65}$ Conversely, breast PRFA is frequently performed under general anesthesia because it is often combined with an axillary sentinel lymph node dissection and excision. ${ }^{62,63}$ Finally, radio frequency ablation of pancreatic lesions can be associated with significant post-procedural discomfort, with some groups advocating a combined general/regional approach with a thoracic epidural for this procedure, as the ablation is typically performed using laparoscopic surgery.

\section{Conclusion}

In summary, PRFA has become a widely accepted treatment modality for many types of solid tumors. Frequently, these procedures are performed outside of the operating room and, as such, require clinicians with some degree of expertise and experience in performing NORA. The anesthetic technique of choice is typically based on the location and the type of lesion to be treated and the experience of the anesthesia provider with these types of procedures. At this time, there are few large-scale trials to inform best practices in caring for these patients but, as with many clinical situations, the clinician must continue to make an assessment of the patient and further develop an anesthetic prescription that best balances the risks and benefits of all related issues for a given patient. Clearly, PRFA and various anesthetic approaches for these procedures represent an area for further prospective investigation to develop best practice guidelines.

\section{Disclosure}

Dr Federico Piccioni reports personal fees and nonfinancial support from MSD Italia and Edwards Lifesciences, outside the submitted work. The authors report no other conflicts of interest in this work.

\section{References}

1. Tatl S, Tapan U, Morrison PR, Silverman SG. Radiofrequency ablation: technique and clinical applications. Diagn Interv Radiol. 2012;18:508-516. doi:10.4261/1305-3825.DIR.5168-11.1

2. Lencioni R, Cioni D, Lera J, et al. Radiofrequency ablation: principles and techniques. In: Lencioni R, Cioni D, Bartolozzi C, editors. Focal Liver Lesions. Detection, Characterization, Ablation. Berlin: Springer Verlag; 2005:307-316.
3. Beermann M, Lindeberg J, Engstrand J, et al. 1000 consecutive ablation sessions in the era of computer assisted image guidance - lessons learned. Eur J Radiol Open. 2019;6:1-8. doi:10.1016/j.ejro.2018.11.002

4. Hinkelbein J, Lamperti M, Akeson J, et al. European society of anaesthesiology and European Board of Anaesthesiology guidelines for procedural sedation and analgesia in adults. Eur J Anaesthesiol. 2018;35:6-24. doi:10.1097/EJA.0000000000000683

5. Pino RM. The nature of anesthesia and procedural sedation outside of the operating room. Curr Opin Anaesthesiol. 2007;20:347-351. doi:10.1097/ACO.0b013e32827035c7

6. Eichhorn V, Henzler D, Murphy MF. Standardizing care and monitoring for anesthesia or procedural sedation delivered outside the operating room. Curr Opin Anaesthesiol. 2010;23:494-499. doi:10.1097/ACO.0b013e32833b9c9f

7. Chehab MA, Thakor A, Tulin-Silver S, et al. Adult and pediatric antibiotic prophylaxis during vascular and IR procedures: a Society of Interventional Radiology practice parameter update endorsed by the Cardiovascular and Interventional Radiological Society of Europe and the Canadian Association for Interventional Radiology. $J$ Vasc Interv Radiol. 2018;29:1483-1501.e2. doi:10.1016/j.jvir.2018.06.007

8. Mazzaferro V, Battiston C, Perrone S, et al. Radiofrequency ablation of small hepatocellular carcinoma in cirrhotic patients awaiting liver transplantation: a prospective study. Ann Surg. 2004;240:900-909. doi:10.1097/01.sla.0000143301.56154.95

9. Lee MW, Raman SS, Asvadi NH, et al. Radiofrequency ablation of hepatocellular carcinoma as bridge therapy to liver transplantation: a 10-year intention-to-treat analysis. Hepatology. 2017;65(6):1979-1990. doi:10.1002/hep.29098

10. Bertot LC, Sato M, Tateishi R, Yoshida H, Koike K. Mortality and complication rates of percutaneous ablative techniques for the treatment of liver tumors: a systematic review. Eur Radiol. 2011;21:2584-2596. doi:10.1007/s00330-011-2222-3

11. Lee S, Rhim H, Kim YS, et al. Percutaneous radiofrequency ablation of hepatocellular carcinomas: factors related to intraprocedural and postprocedural pain. AJR Am J Roentgenol. 2009;192(4):1064-1070. doi:10.2214/AJR.08.1350

12. Wu J, Lu Y, Cao X. Different effects of oxycodone and remifentanil in patients undergoing ultrasound guided percutaneous radiofrequency ablation of hepatic cancer: a randomized trial. Drug Des Devel Ther. 2019;13:365-372. doi:10.2147/DDDT.S188728

13. Amornyotin S, Jirachaipitak S, Wangnatip S. Anesthetic management for radiofrequency ablation in patients with hepatocellular carcinoma in a developing country. $J$ Anesth Crit Care. 2015;3(1):00086.

14. Yokoyama K, Ikeda O, Kawanaka K, et al. Pain control in patients with hepatocellular carcinoma treated by percutaneous radiofrequency ablation: comparison of the efficacy of one-shot and continuous intravenous fentanyl delivery. Acta Radiol. 2014;55 (10):1219-1225. doi: $10.1177 / 0284185113519623$

15. Al-Rifai Z, Mulvey D. Principles of total intravenous anaesthesia: practical aspects of using total intravenous anaesthesia. BJA Educ. 2016;16(8):276-280. doi:10.1093/bjaed/mkv074

16. Joung KW, Choi SS, Jang DM, et al. Comparative effects of dexmedetomidine and propofol on US-guided radiofrequency ablation of hepatic neoplasm under monitored anesthesia care. a randomized controlled study. Medicine. 2015;94(32):e1349. doi:10.1097/MD.0000000000001349

17. Jia Q, Tian F, Duan WN, et al. Effects of dezocine-remifentanil intravenous anaesthesia on perioperative signs, Serum TNF- $\alpha$ and IL-6 in liver cancer patients undergoing radiofrequency ablation. $J$ Coll Physicians Surg Pak. 2019;29(1):4-7. doi:10.29271/jcpsp.2019.01.4

18. Wong J, Lee KF, Lee PS, et al. Radiofrequency ablation for 110 malignant liver tumours: preliminary results on percutaneous and surgical approaches. Asian J Surg. 2009;32:13-20. doi:10.1016/ S1015-9584(09)60003-8

19. Cheung Ning M, Karmakar MK. Right thoracic paravertebral anaesthesia for percutaneous radiofrequency ablation of liver tumours. $\mathrm{Br}$ J Radiol. 2011;84:785-789. doi:10.1259/bjr/28983063 
20. Piccioni F, Fumagalli L, Garbagnati F, et al. Thoracic paravertebral anesthesia for percutaneous radiofrequency ablation of hepatic tumors. J Clin Anesth. 2014;26(4):271-275. doi:10.1016/j.jclinane.2013.11.019

21. Gazzera C, Fonio P, Faletti R, et al. Role of paravertebral block anaesthesia during percutaneous transhepatic thermoablation. Radiol Med. 2014;119(8):549-557. doi:10.1007/s11547-013-0372-x

22. Abu Elyazed MM, Abdullah MA. Thoracic paravertebral block for the anesthetic management of percutaneous radiofrequency ablation of liver tumors. J Anaesthesiol Clin Pharmacol. 2018;34(2):166-171. doi:10.4103/joacp.JOACP_39_17

23. Kim H, Kim Y, Kim BJ, et al. The effectiveness of ultrasound-guided thoracic paravertebral block for percutaneous radiofrequency ablation of hepatic tumors: a pilot study. J Korean Soc Radiol. 2018;79 (6):323-331. doi:10.3348/jksr.2018.79.6.323

24. Karmakar MK. Thoracic paravertebral block. Anesthesiology. 2001;95:771-780. doi:10.1097/00000542-200109000-00033

25. Lai R, Peng Z, Chen D, et al. The effects of anesthetic technique on cancer recurrence in percutaneous radiofrequency ablation of small hepatocellular carcinoma. Anesth Analg. 2012;114(2):290-296. doi:10.1213/ANE.0b013e318239c2e3

26. Choi EJ, Choi YM, Kim HJ, et al. The effects of thoracic epidural analgesia during percutaneous radiofrequency ablation for hepatocellular carcinoma. Pain Res Manag. 2018;2018:4354912. doi:10.1155/2018/ 4354912

27. Yeung JH, Gates S, Naidu BV, Wilson MJ, Gao Smith F. Paravertebral block versus thoracic epidural for patients undergoing thoracotomy. Cochrane Database Syst Rev. 2016;2:CD009121. doi:10.1002/14651858.CD004158.pub3

28. Stone MJ, Venkatesan AM, Locklin J, et al. Radiofrequency ablation of renal tumors. Tech Vasc Interv Radiol. 2007;10(2):132-139. doi:10.1053/j.tvir.2007.09.011

29. Ljungberg B, Bensalah $\mathrm{K}$, Canfield $\mathrm{S}$, et al. EAU guidelines on renal cell carcinoma: 2014 update. Eur Urol. 2015;67(5):913-924. doi:10.1016/j.eururo.2015.01.005

30. Lorber G, Glamore M, Doshi M, Jorda M, Morillo-Burgos G, Leveillee RJ. Long-term oncologic outcomes following radiofrequency ablation with real-time temperature monitoring for $\mathrm{T} 1 \mathrm{a}$ renal cell cancer. Urol Oncol. 2014;32:1017e23. doi:10.1016/j. urolonc.2014.03.005

31. Zhao X, Wang W, Zhang S, et al. Improved outcome of percutaneous radiofrequency ablation in renal cell carcinoma: a retrospective study of intraoperative contrastenhanced ultrasonography in 73 patients. Abdom Imaging. 2012;37:885-891. doi:10.1007/s00261-011-9828-4

32. Mayo-Smith WW, Dupuy DE, Parikh PM, Pezzullo JA, Cronan JJ. Imaging-guided percutaneous radiofrequency ablation of solid renal masses: techniques and outcomes of 38 treatment sessions in 32 consecutive patients. AJR Am J Roentgenol. 2003;180:1503-1508. doi:10.2214/ajr.180.6.1801503

33. Gervais DA, McGovern FJ, Arellano RS, McDougal WS, Mueller PR. Radiofrequency ablation of renal cell carcinoma: part 1, indications, results, and role in patient management over a 6-year period and ablation of 100 tumors. AJR Am J Roentgenol. 2005;185:64e71.

34. Park BK, Kim CK, Lee HM. Image-guided radiofrequency ablation of Bosniak category III or IV cystic renal tumors: initial clinical experience. Eur Radiol. 2008;18:1519e25. doi:10.1007/s00330-008-0891-3

35. Zagoria RJ, Pettus JA, Rogers M, Werle DM, Childs D, Leyendecker JR. Long-term outcomes after percutaneous radiofrequency ablation for renal cell carcinoma. Urology. 2011;77:1393e7. doi:10.1016/j.urology.2010.12.077

36. Kim HJ, Park BK, Chung IS. Comparison of general anesthesia and conscious sedation during computed tomography guided radiofrequency ablation of T1a renal cell carcinoma. Can Assoc Radiol J. 2018;69(1):24-29. doi:10.1016/j.carj.2017.07.003

37. Pereira PL, Masala S. Standards of practice: guidelines for thermal ablation of primary and secondary lung tumors. Cardiovasc Intervent Radiol. 2012;35:247-254. doi:10.1007/s00270-012-0340-1
38. Dupuy DE, Mayo-Smith WW, Abbott GF, DiPetrillo T. Clinical applications of radiofrequency tumor ablation in the thorax. Radiographics. 2002;22:259-269. doi:10.1148/radiographics.22.suppl_1.g02oc03s259

39. Steinke K, Sewell PE, Dupuy D, et al. Pulmonary radiofrequency ablation: an international study survey. Anticancer Res. 2004;24:339-343.

40. Okuma T, Matsuoka T, Yamamoto A, et al. Frequency and risk factors of various complications after computed tomography-guided radiofrequency ablation of lung tumors. Cardiovasc Intervent Radiol. 2008;31:122-130. doi:10.1007/s00270-007-9225-0

41. De Baere T, Tselikas L, Catena V, et al. Percutaneous thermal ablation of primary lung cancer. Diagn Interv Imaging. 2016;97:1019-1024. doi:10.1016/j.diii.2016.08.016

42. Chan VO, McDermott S, Malone DE, Dodd JD. Percutaneous radiofrequency ablation of lung tumors evaluation of the literature using evidence-based techniques. $J$ Thorac Imaging. 2011;26:18-26. doi:10.1097/RTI.0b013e3181e48d5e

43. De Baere T, Palussiere J, Auperin A, et al. Mid-term local efficacy and survival after radiofrequency ablation of lung tumors with a mini-mum follow-up of 1 year: prospective evaluation. Radiology. 2006;240:587-596. doi:10.1148/radiol.2402050807

44. Simon CJ, Dupuy DE, DiPetrillo TA, et al. Pulmonary radiofrequency ablation: long-term safety and efficacy in 153 patients. Radiology. 2007;243:268-275. doi:10.1148/radiol.2431060088

45. Lencioni R, Crocetti L, Cioni R, et al. Response to radiofrequency ablation of pulmonary tumours: a prospective, intention-to-treat, multicentre clinical trial (the RAPTURE study). Lancet Oncol. 2008;9:621-628. doi:10.1016/S1470-2045(08)70155-4

46. Hoffmann RT, Jakobs TF, Lubienski A, et al. Percutaneous radiofrequency ablation of pulmonary tumors. Is there a difference between treatment under general anaesthesia and under conscious sedation? Eur J Radiol. 2006;59:168-174. doi:10.1016/j.ejrad.2006.04.010

47. Yasui K, Kanazawa S, Sano Y, et al. Thoracic tumors treated with CT-guided radiofrequency ablation: initial experience. Radiology. 2004;231(3):850-857. doi:10.1148/radiol.2313030347

48. Ruscio L, Planche O, Zetlaoui P, Benhamou D. Percutaneous radiofrequency ablation of pulmonary metastasis and thoracic paravertebral block under computed tomographic scan guidance: a case report. A A Pract. 2018;11(8):213-215. doi:10.1213/XAA.0000000000000784

49. vanSonnenberg E, Shankar S, Morrison PR, et al. Radiofrequency ablation of thoracic lesions: part 2, initial clinical experience-technical and multidisciplinary considerations in 30 patients. AJR Am $J$ Roentgenol. 2005;184:381-390. doi:10.2214/ajr.184.2.01840381

50. Kurup AN, Callstrom MR. Image-guided percutaneous ablation of bone and soft tissue tumors. Semin Intervent Radiol. 2010;27 (3):276-284. doi:10.1055/s-0030-1261786

51. Tomasian A, Wallace AN, Hillen TJ, Jennings JW. Percutaneous ablation in painful bone tumors. Semin Musculoskelet Radiol. 2016;20:472-485. doi:10.1055/s-0036-1594281

52. Callstrom MR, Charboneau JW, Goetz MP, et al. Painful metastases involving bone: feasibility of percutaneous CT- and US-guided radio-frequency ablation. Radiology. 2002;224:87-97. doi:10.1148/ radiol.2241011613

53. Goetz MP, Callstrom MR, Charboneau JW, et al. Percutaneous image-guided radiofrequency ablation of painful metastases involving bone: a multicenter study. J Clin Oncol. 2004;22:300-306. doi:10.1200/JCO.2004.03.097

54. Thanos L, Mylona S, Galani P, et al. Radiofrequency ablation of osseous metastases for the palliation of pain. Skeletal Radiol. 2008;37:189-194.

55. Dupuy DE, Liu D, Hartfeil D, et al. Percutaneous radiofrequency ablation of painful osseous metastases. Cancer. 2010;116:989-997. doi:10.1002/cncr.v116:4

56. Botsa E, Mylona S, Koutsogiannis I, Koundouraki A, Thanos L. CT image guided thermal ablation techniques for palliation of painful bone metastases. Ann Palliat Med. 2014;3(2):47-53. doi:10.3978/j. issn.2224-5820.2014.04.02 
57. Thacker PG, Callstrom MR, Curry TB, et al. Palliation of painful metastatic disease involving bone with imaging-guided treatment: comparison of patients' immediate response to radiofrequency ablation and cryoablation. AJR Am J Roentgenol. 2011;197:510-515. doi:10.2214/AJR.10.6029

58. D'Onofrio M, Crosara S, De Robertis R, et al. Percutaneous radiofrequency ablation of unresectable locally advanced pancreatic cancer: preliminary results. Technol Cancer Res Treat. 2017;16 (3):285-294. doi:10.1177/1533034616649292

59. Wolf FJ, Dupuy DE, Machan JT, Mayo-Smith WW. Adrenal neoplasms: effectiveness and safety of CT-guided ablation of 23 tumors in 22 patients. Eur J Radiol. 2012;81:1717-1723. doi:10.1016/j.ejrad.2011.04.054

60. Lim HK, Baek JH, Lee JH, et al. Efficacy and safety of radiofrequency ablation for treating locoregional recurrence from papillary thyroid cancer. Eur Radiol. 2015;25:163-170. doi:10.1007/s00330-014-3405-5

61. Park HS, Baek JH, Park AW, Chung SR, Choi YJ, Lee JH. Thyroid radiofrequency ablation: updates on innovative devices and techniques. Korean J Radiol. 2017;18:615-623. doi:10.3348/kjr.2017.18.4.615
62. Oura S, Tamaki T, Hirai I, et al. Radiofrequency ablation therapy in patients with breast cancers two centimeters or less in size. Breast Cancer. 2007;14:48-54. doi:10.2325/jbcs.14.48

63. Yamamoto N, Fujimoto H, Nakamura R, et al. Pilot study of radiofrequency ablation therapy without surgical excision for $\mathrm{T} 1$ breast cancer: evaluation with MRI and vacuum-assisted core needle biopsy and safety management. Breast Cancer. 2011;18:3-9. doi:10.1007/s12282-0100197-6

64. Peek MCL, Ahmed M, Napoli A, Usiskin S, Baker R, Douek M. Minimally invasive ablative techniques in the treatment of breast cancer: a systematic review and meta-analysis. Int $J$ Hyperthermia. 2017;33(2):191-202. doi:10.1080/02656736.2016. 1230232

65. Kim JH, Baek JH, Lim HK, et al. 2017 thyroid radiofrequency ablation guideline: Korean Society of Thyroid Radiology. Korean J Radiol. 2018;19(4):632-655. doi:10.3348/kjr.2018.19.4.632

\section{Publish your work in this journal}

Local and Regional Anesthesia is an international, peer-reviewed, open access journal publishing on the development, pharmacology, delivery and targeting and clinical use of local and regional anesthetics and analgesics. The journal welcomes submitted papers covering original research, basic science, clinical studies, reviews \& evaluations, guidelines, expert opinion and commentary, case reports and extended reports. The manuscript management system is completely online and includes a very quick and fair peer-review system, which is all easy to use. Visit http://www.dovepress.com/testimonials. php to read real quotes from published authors. 